\title{
TEACHER-TRAINERS' PERCEPTION OF THE CAUSES AND TREATMENT OF SLEEP-WALKING DISORDER IN CHILDREN
}

\author{
Omozuwa, Margaret Osarugue \\ School of Education \\ College of Education \\ Ekiadolor - Benin \\ and \\ Iyamu, Ede O. S. PhD \\ Assoc. Professor \\ Department of Educational Psychology \& Curriculum Studies \\ University of Benin \\ eosiyamu@yahoo.com
}

\begin{abstract}
This study investigated the perception of NCE teacher trainers on the causes and treatment of sleepwalking disorder in children. Descriptive survey design was adopted for the study. A sample of sixty respondents (thirty males and thirty females) where selected for the study. Two research questions and two hypotheses guided the study. Data was collected using structured questionnaire [NCE Trainers Perception of the Causes and Treatment of Sleepwalking Disorder in Children (NTPCTSD)] designed by the researchers. Simple percentages were used for analyzing the data. The result showed that respondents indicated Tiredness (98.1\%), Night mare (83.6\%), Fever (70.1\%) and sleep deprivation (67.6\%) as the causes of sleepwalking disorder.The study also revealed that majority of the respondents perceived anticipatory awakening $(98 \%)$ as a vital treatment of sleep walking disorder. Based on the findings recommendations are made.
\end{abstract}

Keywords: Sleepwalking Disorder, Rapid Eye Movement (REM), NonRapid Eye Movement (NREM),

\section{Introduction}

Sleep disorder is as old as man's existence and is mainly common among children aged $6-12$ years. The disorder presents a lot of worry to the parents, guardian and friends of the sleepwalker and an embarrassment to the affected who does not remember the sleepwalking episode. 
According to Afolabi, \& Imhonde (2003), sleep-walking is basically a particular loss of consciousness characterized by a variety of behavioural and neo-physiological effects. Sleepwalking is a complex process regulated by the brain and it obeys a 24 hours biological clock (Awake. March 22.2003). In modern psychology, sleep and the various stages of sleep are typically defined and characterized by particular psychological events, in particular brain wave patterns as recorded by an electrocephalograph, metabolic process, muscle tone, heart and respiratory rates and the important presence or absence of rapid eye movement. The typical division is into Rapid Eye Movement (REM) sleep and Non Rapid Eye Movement (NREM) sleep. Sleep walking, according to Reid (1989), is a condition in which a person who appears not to be governed by normal will or capable of normal grasp of the environment, walks or performs other motor acts, beginning during or immediately after sleep and who does not recall the actions after awakening. The condition is also known as somnambulism. Sleepwalking is much more common in children than in adults occurring in about $5 \%$ of children (Kelvin 2005). Kelvin further stated that sleep walking (Somnambulism) is a sleep disorder characterized by walking or other activities while seemingly still asleep. It is a series of complex behaviour that is initiated during slow wave sleep and results in walking during sleep. Sleepwalking episode usually lasts from 15 to 30 minutes. Fahy (1988) believes that the risk of injury is common though the myth associated with this is that sleepwalkers do not hurt themselves. Sleep walking itself may be indicative of serious disorder and the phenomenon tends to run in families. It is common in persons of nervous disposition and first episode of renewed episodes are sometimes provoked by events that cause daytime anxiety. In children for example, sleepwalking may follow disharmony while in adults, it may occur in combat neuroses. Persons thus affected may shout in their sleep or jump out of bed and attack imaginary enemies. These actions of most sleepwalkers however are non-violent and appear purposeless. A child for example may walk around slowly with a vacant or sometimes distressed expression; fail to respond when spoken to, or simply grunt as if annoyed. He may sit in a chair, fumble with things and eventually return to bed and normal sleep. Only in rare cases do sleepwalkers fall or hurt themselves. It should be noted however that sleepwalking episode usually begins in Non-Rapid Eye Movement Sleep (NREM). In elderly persons, a similar confused state of automatism may occur following Rapid Eye Movement Sleep (REM) and the individual may get half 
dressed, mutter that he must catch the bus to work and stumble around the house. This type of incident is common in elderly persons with some impaired brain function as in senility or other disease conditions. Roseland (2004) outlines six characteristics needed to support a diagnosis of sleepwalking disorder. The 1st four agree with those identified by Carpenter \& Buchanan (1994).

1. Repeated episode of arising from sleep and walking about usually from the first to third of the major sleep period.

2. A blank staring face, relative unresponsiveness to others, and an inability to be awakened except with great difficulty during sleepwalking.

3. Amnesia of the episode after full awakening.

4. Some confusion or disorientation after awakening.

5. Chemically significant distress or impairment in social, occupational or other important functioning related to sleep walking

6. Lack of evidence that the disturbance is due to the direct effect of a substance such as drug abuse, a medication or a general medical condition.

\section{Causes of Sleep Walking Disorder}

Kupfer \& Raynolds (1992) believe that sleep-walking can be caused by environmental and physiological factors. Environmental factors include sleep deprivation; disorganized sleep schedules, fever, stress, magnesium deficiencies and alcohol intoxicant can trigger sleepwalking. Drugs, narcoleptics (drugs used to treat psychosis) major tranquilizers (drugs that increase activity) and antihistamines (drugs used to treat symptoms of allergy) can cause sleepwalking.

Psychological factors include conditions that increase the frequency of sleepwalking. The length and depth of slow wave sleep, which is greater in young children, may be a factor in the increased frequency of sleepwalking in children. Kupfer \& Reynolds further stated that sleepwalking symptoms include ambulation (walking and moving about) that occurs during sleep. The onset typically occurs in pre-pubertal children.

\section{Treatment of Sleep Walking Disorder.}

Kupfer \& Reynolds (1992) suggest the following as treatment for sleepwalking:

(1) Develop calming bedtime rituals, keep a safe sleeping environment 
(2) Be involved in relaxation exercise because stress can be a trigger for sleepwalking.

(3) Get plenty of rest as being overtired can trigger a sleep walking episode;

(4) Remove anything from the bedroom that can be hazardous or harmful.

(5) The sleepwalkers' bedroom should be on the ground floor of the house to avoid falling from stairs during sleepwalking episode.

(6) The possibility of patients opening windows or doors should be eliminated.

(7) Hypnosis is helpful for both children and adults.

(8) An assessment of the sleepwalker should include a careful review of the current medication so that modification can be made if necessary.

(9) Clonazepan (klonopin) in low doses before bedtime and continued 3 - 6 weeks is usually effective.

(10) A small dose of diazepam or Lorazepam eliminates the episode or considerably reduces them.

(11) Relaxation techniques, mental imaginary and anticipatory awakening are chosen for long term treatment of persons with sleepwalking disorder. Anticipatory awakening consists of waking the child or person approximately 15 - 20 minutes before the usual time of an event and then keeping him awake through the time during which the events usually occur. Relaxation and mental imagery should be undertaken only with the help of an experienced behavioural therapist or hypnotist.

\section{Statement of Problem}

The researchers are worried about the alarming increase of sleep-walking disorder in children in our society and the increasing indifference on the part of the Government and the public about how this problem can be treated .Families of sleep walkers most often ignorantly do not see this disorder as a problem and others who do, are confused not knowing the appropriate treatment. Such families therefore resort to attributing the cause and treatment to religion (spirituality), stigmatization and labelling of the victim. Based on the foregoing, the researchers hope to find out the perception of NCE trainers on the causes and treatment of sleep walking episodes. The researchers believe that the result of this study will help in developing counselling remedies to assist the sleep walker and their families. 


\section{Assumptions of Study}

The researchers made the following assumptions in this study.

1. There are certain factors responsible for sleep walking disorder

2. Sleep walking is a common disorder in the Nigerian society

3. Children and adults experience sleep walking disorder

4. Children who experience sleepwalking disorder usually outgrow it

5. Sleepwalking disorder can be treated

\section{Purpose of Study}

This study hopes to develop counselling remedies to assist the sleep walker.

\section{Research Questions}

This study answered the following research questions.

1. What are the possible causes of sleep walking disorder in children as perceived by male and female teacher trainers?

2. How do married and unmarried teacher trainers perceive the various treatments used for sleep walking disorder in children?

\section{Research Methodology}

The study was a descriptive survey designed to find out the opinion of NCE teacher trainers on the causes and treatment of sleep walking disorder in children. The population of the study comprised all NCE trainers of the College of Education, Ekiadolor. The sample for the study was sixty respondents made up of thirty males and thirty females selected using the purposive sampling technique.

\section{Instrument for Data Collection}

The research was conducted with the use of a questionnaire. The questionnaire was designed to collect information about the causes and treatment of sleep walking disorder in children as perceived by NCE Teacher Trainers. The instrument used for the study was NCE Trainers Perception of the Causes and Treatment of Sleep Walking Disorder in Children (NTPCTSD).The questionnaire consisted of three sections. The first section contained personal bio-data (demographic data). The second section contained eight items on causes of sleep walking disorder while the third section contained eight items on the treatment of sleep walking disorder. The items on the questionnaire were drawn based on various sources of literature which point to the causes and treatment of sleepwalking disorder in children aged 6-21 years. After having the 
investment validated by some lecturers in the Department of Guidance and Counselling, College of Education Ekiadolor. A reliability test was carried out in 20 respondents in the college who were not part of the sample of the study. Using the test, re-test method, the score obtained from the administration of the questionnaire were correlated using the Pearson moment correlation co-efferent. The reliability index of 8.85 was obtained. The data collected were analyzed using simple percentages. The responses to the items were considered significant if over fifty percent of the respondents gave a 'yes' answer as response while responses below fifty percent were regarded as not significant.

\section{Results}

Tables 1 and 2 represent in percentages the opinion of male and female, married and unmarried NCE Trainers in College of Education Ekiadolor on the causes and treatment of sleep walking disorder in children aged 6-12 years.

Table 1 Percentage scores of male and female respondents on the causes of sleep walking disorder in children $(\mathrm{N}=60)$

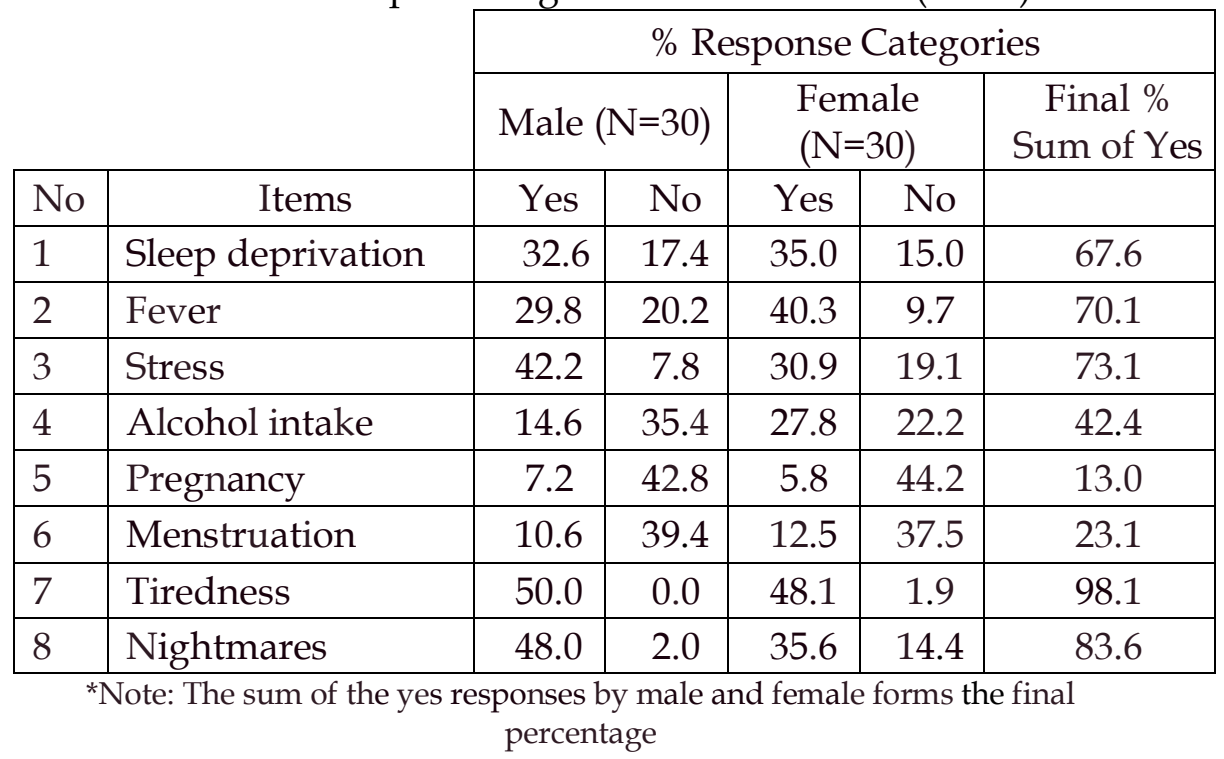

Table 1 shows that out of the eight causes of sleep walking disorder, such as sleep deprivation, fever, stress, alcohol intake, pregnancy, menstruation, tiredness and nightmare only five were significant. These include tiredness (98.1\%), nightmare (83.6\%), stress $(73.1 \%)$, fever $(70.1 \%)$ and sleep deprivation $(67.6 \%)$. The 
insignificant causes of sleepwalking disorder as indicated by the respondents are alcohol (42.4\%), menstruation $(23.1 \%)$ and pregnancy $(13.0 \%)$

Table 2 Percentage scores of married and unmarried respondents on the treatment of sleep walking disorder in children $(\mathrm{N}=60)$

\begin{tabular}{|c|c|c|c|c|c|c|}
\hline \multirow[b]{3}{*}{ No } & \multirow[b]{3}{*}{ Items } & \multicolumn{5}{|c|}{ \% Response Categories } \\
\hline & & \multicolumn{2}{|c|}{ Male $(\mathrm{N}=30)$} & \multicolumn{2}{|c|}{$\begin{array}{l}\text { Female } \\
(\mathrm{N}=30)\end{array}$} & \multirow[t]{2}{*}{$\begin{array}{c}\text { Final \% } \\
\text { Sum of } \\
\text { Yes }\end{array}$} \\
\hline & & Yes & No & Yes & No & \\
\hline 1 & Sufficient Rest & 48.1 & 1.9 & 25.6 & 14.4 & 73.7 \\
\hline 2 & Hypnosis & 23.5 & 17.5 & 30.1 & 19.9 & 53.6 \\
\hline 3 & Relaxation & 35.0 & 15.0 & 26.9 & 23.1 & 61.9 \\
\hline 4 & Anticipatory Awakening & 50.0 & 0.0 & 48.8 & 2.0 & 98.0 \\
\hline 5 & $\begin{array}{l}\text { Less intake of water before } \\
\text { sleep }\end{array}$ & 30.0 & 20.0 & 25.5 & 14.5 & 65.5 \\
\hline 6 & Drugs & 27.6 & 12.4 & 10.7 & 39.3 & 38.3 \\
\hline 7 & Balanced Diet & 2.0 & 48.0 & 6.2 & 43.8 & 8.2 \\
\hline 8 & Gastronomic Food & 10.5 & 39.5 & 9.6 & 40.4 & 20.1 \\
\hline
\end{tabular}

*Note: The sum of the yes responses by married and unmarried respondents forms the final percentages

Table 2 shows that out of the various treatments of sleep walking disorder such as sufficient rest, hypnosis, relaxation, anticipatory awakening, less water intake before sleep, drugs, balanced diet and gastronomic food, only five were significant. These were Anticipatory Awakening (98.0\%), Rest (73.7\%), less water intake before sleep (65.5\%), Relaxation (61.9\%) and Hypnosis $(53.6 \%)$. The insignificant treatment of sleep walking disorder indicated by the respondents were drugs (38.3\%), Gastronomic food $(20.1 \%)$ and Balanced diet $(8.2 \%)$

\section{Discussions of Findings}

The findings of the study reveal the respondents' opinion on the causes of sleep walking disorder in children as: Tiredness $(98.1 \%)$, Nightmare $(83.6 \%)$, Stress $(73.1 \%)$, Fever $(70.1 \%)$ and sleep 
deprivation $(67.6 \%)$. This is in line with the earlier researches which suggest that these factors have been consistently associated with sleep walking in both developed and developing countries (Kupfer \& Reynolds 1992). One could summarize from the literature reviewed that sleep walking disorder can be caused by stress, fever, taking of substance like alcohol and excessive drinking of water before sleeping at night (Roseland 2004). The study also revealed that in terms of treatment of sleep walking disorder in children, the most significant was Anticipatory awaking (98\%). This emphatically shows that the respondents perceived this factor as a reliable therapy. This supports the idea of Kupfer \& Reynolds (1992) that anticipatory awaking and relaxation techniques are long-term treatment of persons with sleep walking disorder.

\section{Recommendations}

Based on the findings, the following recommendations are proposed:

i. The Government should organize seminars for school children, parents, academic and non academic staff of institutions about the causes and treatment of sleepwalking disorder.

ii. Governmental Organizations, market women forum, clubs, churches, mosques and other organizations should be encouraged to attend such seminars with trained counsellors as resources persons with good incentive. The following could be taught in the workshops/seminars organized to eradicate sleepwalking:

- Non-use of alcohol or central nervous system depressants if prone to sleepwalking

- Non- involvement in fatigue because this can instigate sleepwalking episode and

- Avoiding or minimizing stress, anxiety and conflict, which can worsen the condition of a sleepwalker.

This study has identified that sleepwalking disorder is associated with causal factors as tiredness, nightmare, stress, fever and sleep deprivation. There is also available evidence that anticipatory awakening is a vital therapy in the treatment of sleepwalking disorder in children. Unless these factors are addressed, and appropriate remedies sought, the problem of sleep 
walking sickness of children and adult alike is to be on the increase in the society. As more people become aware of the causes of sleepwalking and equipped to manage it, the eradication of this problem is likely to be in sight.

\section{References}

Afolabi, A. O. \& Imhonde, H. O. (2003). Psychology: An Introduction, Benin City. Ever - Bless.

American Psychiatric Association (1994) Diagnostic and Statistical Manual of mental disorder. Washington D.C

Awake: Sleep, Luxury or Necessity (March 22, 2003). Watch Tower Bible and Tract Society. Pennsylvania.

Carpenter, W. T. \& Buchanan, R. W. (1994). Schizophrenia New England Journal of Medicine.

Carson, R. C., Butcher, J. N. \& Mineka, S. (2000). Abnormal Psychology and Modem Life (11 th ed.). Allyn and Bacon, Boston.

Fahy, T. A, (1988). The diagnosis of multiple personality. A critical review.

British journal of psychiatry. 153,597 - 606.

Kelvin S. (2005) MA Review: Verimed Health Care. Adam Health Illustrated Encyclopedia, Boston.

Kluft, R. P. (1987). An update in multiple personality disorder. Hospital and Community Psychiatry, 38, 363 - 373.

Kupfer, D. J. \& Reynolds, C. F. III (1992). Sleep and affective disorder. In disorders paykel (Ed.), Handbook of affective disorders (2nd ed., pp. 311 - 323). New York: Guilford Press.

Reid W. H. (1989): The Treatment of psychiatric disorder. New York.

Bruanzel

Robins 1. N \& Cottier L .. (1995) Diagnosis. interview schedule for DSM IV S10 Louis Washington University Press

Roseland C. (2004) A steep disorder, a legal dilemma and a psychological challenge. Rosalind Cartwright

Wong, M. M., Brower, K. K.\& Titzgerant (2004): Sleep problems in early childhood and Adolescent: Clinical and experimental Research 28. 258-587

Zimbado P. G. Weber A. \& Johnson R. (2000) Psychology (3rd edition) Allyn and Bacon. U.S.A 